\title{
Uma teoria tentativa ${ }^{1}$ \\ José Luiz Braga
}

\section{Resumo}

Proposições teóricas envolvidas em uma pesquisa empírica constituem o eixo deste artigo. Discute preliminarmente a hipótese heurística que direciona a pesquisa: 0 conceito de dispositivos interacionais, caracterizado como fator empírico comum para organizar uma diversidade aparentemente caótica de processos de comunicação. A partir dessa heurística, são tratadas as relações entre episódios comunicacionais e dispositivos; elementos codificados e inferenciais no dispositivo; e condições básicas para aproximação metodológica, referentes a descrições, valorações e transversalidade. 0 artigo relaciona a hipótese ao problema específico da pesquisa em curso; e a uma questão abrangente sobre conhecimento em Comunicação. Esse problema geral direciona a investigação e estipula 0 sentido da proposição teórica.

\section{Palavras-chave}

Dispositivos interacionais. Epistemologia. Pesquisa em Comunicação.

José Luiz Braga | jlbraga@via-rs.net Doutor em Comunicação pela Universidade de Paris 2. Professor do Programa de Pós-Graduação em Ciências da Comunicação da Universidade do Vale do Rio dos Sinos (Unisinos).

\section{Introdução}

0 ponto de partida da reflexão a ser desenvolvida no artigo é o questionamento posto por Luiz Signates, no GT de Epistemologia da Comunicação da XX Compós, em 2011, no debate sobre 0 artigo Dispositivos interacionais: embora negássemos um desenvolvimento teorizante, enfatizando a preocupação empírica e pragmática da proposta, estaríamos na verdade buscando apresentar uma Teoria da Comunicação. A resposta imediata foi no sentido de recusar essa perspectiva e insistir na visada pragmática.

Refletindo sobre a questão, percebemos depois que essa posição excludente é simplificadora. Se entendermos que propor uma "Teoria da Comunicação" corresponde a uma visada abrangente, explicativa, que torne as abordagens diversificadas da área variações dentro de um corpo coerente de conhecimentos - podemos efetivamente reafirmar que a pesquisa não se volta para a proposição de uma teoria da Comunicação. É preciso, entretanto, examinar o que a pesquisa 
pretende fazer, em sua aproximação empírica, para apreender, a partir daquela questão, a teoria implicada no projeto.

A pesquisa específica é um estudo de casos múltiplos. Cerca de dez dispositivos interacionais acionados em determinados episódios comunicacionais devem ser analisados.

Nos artigos estudados durante uma pesquisa desenvolvida entre 2008 e 2011, ao buscar os tipos de fenômenos observados - as ações comunicacionais enfocadas pelos artigos estudados - constatamos uma boa variedade de processos reconhecíveis como modos culturalmente desenvolvidos para exercer uma ação comunicacional. Por exemplo: processos de informação; de crítica; de estimulação da experiência estética; de entretenimento; de aprendizagem; de polêmica; de persuasão; do que tem sido denominado de "autoajuda"; processos de formação de comportamentos e atitudes; processos formadores de opinião; de interpretação/ apropriação; de reposição em circulação, ou "resposta social"; entre muitos outros.

Em cada modo ou processo social, a sociedade experimenta modos de interagir. Tais práticas acabam se tornando disponíveis para a sociedade, "modelando" os processos comunicacionais acionados. Correlatamente, 0 episódio comunicacional que aciona esses modelos lhes dá forma, sentido, substância e direcionamento. A essas matrizes disponíveis na sociedade, propomos denominar "dispositivos interacionais".

Os processos comunicacionais compõem variadas faixas de conhecimento estabelecido e interessam a diversas Ciências Humanas e Sociais (CHS), assim como a diferentes áreas de pesquisa em Comunicação. A pesquisa em pauta estuda casos singulares variados, tomando-os, entretanto como processos de uma mesma "natureza" - para observar, aí, como a comunicação se desenvolve. 0 problema se concentra no seguinte eixo: como, apesar de sua diversidade, complexidade de fatores, variação extraordinária de realizações específicas, tais modos parecem funcionar enquanto dispositivos de interação?

Isso leva à necessidade de esclarecer conceitual e empiricamente 0 que seriam e como operam os dispositivos interacionais apropriados nessa diversidade de processos. Como podemos, sobreposta à variedade reconhecida de casos e situações, perceber essa similaridade que os faz caracterizar a todos como "dispositivos interacionais" em constituição e acionamento?

Uma premissa abrangente, na pesquisa, é a ideia de que os dispositivos interacionais contemporâneos - diretamente midiatizados, 
ou desenvolvidos em zonas de incidência da midiatização - comportam aspectos de codificação bastante flexíveis, dependendo fortemente de invenção e de processos inferenciais. Isso os faz potencialmente voláteis, eventualmente superficiais - gerando experiências comunicacionais frágeis ou fugazes, em decorrência da própria facilidade de substituição. Por sua fragilidade e superficialidade potenciais, são frequentemente processos canhestros ou mesmo decididamente negativos, em termos humanos, e certamente manejáveis por setores dominantes da sociedade.

Por outro lado, essa circunstância histórica (provavelmente transitória, no longo prazo) se oferece como um interregno de amplas possibilidades de experimentação social. Mesmo dispositivos mais ancorados na tradição se diversificam em novas experiências, no contexto da midiatização social. Malgrado sua eventual evanescência, nesse mesmo processo estão sendo testadas tentativas mais duradouras, mais consistentes, mais pregnantes para futuros processos comunicacionais - que só serão percebidas em sua diferença e produtividade social pelos resultados que vierem a produzir.

É cabível, portanto, considerar o interesse em uma ampliação do conhecimento sobre o que há de experimental na midiatização, sobre 0 que ocorre como processo de geração de códigos e para- códigos, sobre o que se solicita e viabiliza como competências inferenciais - em síntese: sobre características de dispositivos interacionais, hoje fortemente impregnados pela midiatização.

Com tal aproximação e tais objetivos empíricos, quando proponho perceber, na diversidade de abordagens e objetos estudados por uma pluralidade de colegas pesquisadores, uma espécie de fator empírico comum ${ }^{2}-0$ dispositivo interacional como lugar geral de ocorrência do comunicacional - é certo que isso implica uma "moção teórica", uma decisão reflexiva que de algum modo deve sustentar a inquirição prevista.

0 que devo tentar esclarecer, então, no presente artigo, são os sentidos teóricos da pesquisa empírica em fase inicial, desenvolvendo reflexivamente a questão posta por Signates. Embora distante de uma proposta de "Teoria da Comunicação", quais são as relações entre minha aproximação pragmática e uma produção de natureza teórica? Ou ainda: que visada teórica se propõe na heurística acionada para minha pesquisa sobre dispositivos interacionais?

A resistência à afirmação de uma teoria, estabelecendo o trabalho na categoria de heurística, pode parecer um gesto de modéstia (pois "produzir teoria" é uma atividade nobre); 
ou uma fuga ao risco de críticas que mais facilmente se abatem sobre proposições muito peremptórias. Pretendemos, diversamente, justificar essa preferência heurística como uma necessidade objetiva para a área, como veremos ao final do texto.

Para caracterizar o elemento teórico contido na pesquisa, com a construção de uma hipótese voltada para determinadas descobertas, procuramos a seguir desenvolver algumas proposições iniciadas no artigo Dispositivos interacionais, justificando a aproximação heurística pretendida. Isso envolve fazer uma reflexão sobre o objeto de investigação da pesquisa; sobre 0 que se pretende inquirir, nesse objeto; e que tipo de descobertas se podem pretender.

\section{0 objeto da investigação}

0 objeto - "dispositivos interacionais" - está preliminarmente elaborado no artigo de mesmo título, apresentado no GT de Epistemologia da Comunicação da XX Compós, em 2011. Trata-se de um modo de observar as interações sociais, procurando condições para estudar empiricamente sua diversidade quase caótica; e propondo uma perspectiva específica segundo a qual não só a singularidade de cada episódio seja ressaltada, mas também processos comuns possam ser percebidos.

Essa elaboração tem como ponto de partida um parti-pris: 0 de que o comunicacional, quaisquer que sejam suas características, se encontra pragmaticamente nas interações entre pessoas e na sociedade em geral. Não assumimos "um valor positivo essencial" em "comunicação". 0 processo social é relevante, mas diversificado em suas realizações: pessoas se comunicam inclusive no conflito, na opressão ou na manipulação. A comunicação só é possível na ocorrência concreta de interações - trata-se então de perceber ocorrências e "lógicas" das interações, na prática social, como o lugar de realização do comunicacional. 0 valor humano da comunicação depende de como tais ocorrências e lógicas são socialmente produzidas. A dificuldade que se coloca é: como estudá-las?

0 conceito de "dispositivos", de Michel Foucault (1980), é nosso ponto de partida. A noção de "sistemas de relações que se produzem entre elementos heterogêneos" é uma pista fundamental. Tratando de um sistema de relações, a perspectiva é, de modo evidente, interessante para estudar interações (comunicacionais).

A percepção de que estes sistemas são historicamente constituídos - não decorrem de "essências" prévias e externas à prática social - é igualmente básica.

Lembramos que Foucault propõe estudos de dispositivos disciplinares - o que o faz enfocar sobretudo processos de regulação. 0 que nos interessa, mais que esse conceito assim especificado, é o que Deleuze (1989, p. 188) considera "uma filosofia dos dispositivos" 
desenvolvida por Foucault, e de que Deleuze assinala características centrais. Dada a extraordinária diversidade de usos subsequentes do conceito (e às vezes apenas da palavra), é importante pôr a ênfase no qualificador. Procuramos desenvolver conceitualmente a noção de "dispositivos interacionais" - é um deslocamento significativo para minha hipótese.

Por isso mesmo sublinho, ao lado dos elementos regrados (que correspondem ao que existe de "código" nas interações), os elementos conjunturais ou contextuais que exigem sempre uma ação inferencial tentativa dos participantes de uma interação.

No estado atual de elaboração do objeto de investigação podemos fazer algumas proposições sobre como o constituímos.

0s episódios interacionais não são mero epifenômeno dos dispositivos. Ao contrário, 0 dispositivo interacional só existe nos episódios concretos que o realizam. A matriz expressa por um episódio não é uma essência que se manifesta, nem uma ideia abstrata referida conscientemente pelos participantes do episódio interacional, mas 0 acionamento de práticas testadas em episódios parecidos (nesse sentido, é um paradigma). É então o resultado de uma transferência, com a carga de reajustes e de improvisação inerentes a toda transferência, feita a partir de outros episódios em que determinados comportamentos pareceram adequados, e nos quais um sistema de relações entre pessoas, ideias e coisas foi desenvolvido ou acionado, propiciando que a interação tenha se desenrolado

Cada episódio é, assim, paradigmático em relação aos demais episódios que possam ser referidos a uma mesma "matriz". Ou talvez melhor: cada episódio participa da constituição da matriz, que só existe pela prática reiterada. Em consequência, os episódios podem se referir mutuamente. $0 \mathrm{~s}$ episódios não são totalmente determinados por processos externos às lógicas da interação, embora certamente sofram todo tipo de incidência de fatores contextuais (sociológicos, linguísticos, psicológicos, neurológicos, culturais etc.).

Em síntese, entendemos que a necessidade prática de comunicar produz dispositivos, tentativamente, de tal forma que estes se comportam como modos para viabilizar a interação. Por sua vez, as interações modificam e reinventam os dispositivos acionados.

Quando as condições contextuais e os processos interacionais (via dispositivos muito estabelecidos) se tornam mutuamente desajustados - pelo enrijecimento codificado do dispositivo e/ou por condições contextuais em mutação - os dispositivos se tornam ineficazes, propiciando ora 0 surgimento de outros dispositivos tentativos concorrentes; ora renovações do próprio dispositivo, com ajustes maiores, através de novas respostas tentativas, a 
contrapelo das respostas-padrão, "reabrindo" 0 dispositivo, que assim se transforma.

0 sistema de relações (a "lógica interacional" que se mantém em episódios sucessivos de acionamento, caracterizando assim o dispositivo) é um padrão compartilhado entre os participantes - e só pode ser compartilhado por estar efetivamente disponível na sociedade. Procedemos por imitação e ajustes, como os estudiosos da cultura bem sabem.

Sendo parcialmente "código" (sistema de regras) o dispositivo é também, na sua realização prática, espaço potencial de desvio, de criação, de ajuste e de "invenção social". Ser espaço de invenção não significa que a invenção será necessariamente positiva, valorável em termos humanos, sociais, psicológicos, estéticos etc. Significa apenas que a sociedade e seus participantes tentam de algum modo desenvolver sistemas de interação para atingir seus objetivos - e ao fazê-lo, a própria ação prática tentativa cria processos.

Para que a interação se realize (ou seja: possa ter alguma continuidade, qualquer que seja seu resultado, quaisquer que sejam os sucessos e as frustrações de cada participante), é preciso que as condições contextuais práticas forneçam sentidos, especificidades, interpretações singulares. Isso solicita dos participantes que façam inferências referentes ao que está singularmente acontecendo e aos direcionamentos que podem ser dados à interação. Essas inferências são cálculos práticos e/ ou "intuitivos" - percepções abdutivas - sobre os elementos acionados como relevantes.

Assim, é importante não enfatizar exclusivamente a questão "controle". Os aspectos de "controle" correspondem ao elemento "código", de que efetivamente não podemos nos subtrair. Sem códigos, não nos comunicamos - por exemplo, a língua ou gestos culturais padronizados. Mas também faz parte do dispositivo interacional o elemento "inferencial", que é tudo o que vincula o processo à circunstância específica, ao aspecto de historicidade não determinada, ao tentativo (justamente porque não-codificado). Essa conceituação é específica para "dispositivos interacionais" - e permite estudar a variação dos elementos e dos sistemas de relações que - com especificidade, a cada caso caracterizam um dispositivo singular e evidenciam suas lógicas próprias.

As regras interacionais são então necessárias, mas não suficientes. A insuficiência não se expressa em necessidade de mais ou melhores regras, mas, diversamente, na exigência de outros processos, como a inferência e o ensaio-e-erro. Além disso, a tentativa do processo ultrapassa as tentativas dos participantes - a própria produção de "códigos interacionais" é tentativa e se fixa ou se dilui na medida mesmo da produção de resultados sociais, conforme os objetivos locais que lhe são atribuídos e que, sabemos, sofrem deslocamentos ou mutações. Isso corresponde a dizer que a produção social de códigos de interação deriva de inferências (tentativas) mais 
ou menos bem sucedidas em perspectiva prática, e que por isso tendem a se fixar e sistematizar diversificadamente. É o que procuramos desenvolver em "Nem rara nem ausente, tentativa" (BRAGA, 2010).

Em situações não habituais, é preciso inventar novos dispositivos. 0 aspecto positivo da situação atual de midiatização é a multiplicação de oportunidades de experimentação. A pluralidade de tentativas, em situações próximas, é inerente ao processo e fundamental para seu desenvolvimento: os dispositivos são selecionados na prática social, e se adaptam sucessivamente (ao mesmo tempo adaptando suas possibilidades e seus acionamentos) por um processo de tipo darwinista: o que se ajusta melhor a um espectro mais amplo de situações aumenta sua chance de replicação e manutenção.

Temos ai a prefiguração de um objeto empírico, organizado para investigação. Esse objeto não é autoevidente (como o são "meios", "produtos midiáticos", "redes sociais" - por exemplo). Logo depende, mais que estes, de conceituação e de caracterização. Mas não é, por isso, menos empírico. 0 que nos interessa, no conceito, é que este viabiliza um modo de observar episódios interacionais diversificados, de efetiva ocorrência na sociedade, relacionados a seu processo produtivo. Temos, no objeto assim delineado, uma possibilidade de um mesmo olhar sobre 0 diverso, permitindo descrever e comparar, nos aproximando do comunicacional que ocorre nessa diversidade.
Tais proposições caracterizam sumariamente nossa hipótese no que se refere ao objeto, nessa fase da investigação. Naturalmente a experiência empírica de investigar certo número de episódios interacionais terá incidências sobre esse desenho, ainda bastante tentativo. Isso pode ser efetivamente considerado como o esboço de uma proposição teórica. A proposição não pretende, porém, explicar - 0 que importa é o que ela permite investigar.

\section{0 quê e como observar}

Três condições básicas de investigação compõem, junto com a construção do objeto, a aproximação teórico-metodológica que desenvolvemos. São premissas que parecem necessárias, nas circunstâncias, para produção de conhecimento na área:

1) buscar uma ênfase descritiva dos observáveis, reduzindo a ênfase explicativa baseada em teorias estabelecidas;

2) reduzir a ênfase valorativa prévia e abrangente, que às vezes acompanha as explicações prontas o julgamento funcionando como "explicação" dos processos observados;

3) finalmente, aproveitar, o mais possível, conhecimentos já desenvolvidos ou em desenvolvimento, produzidos pelo acionamento de teorias diversas sobre objetos diferenciados na área, buscando obter alguma transversalidade. 


\subsection{Descrições}

0 objetivo de favorecer descrições não se coloca sem problemas. Descrever é descrever segundo um determinado ângulo de olhar. Já é, em si, inferencial e propicia inferências relacionados especialmente aos ângulos descritivos adotados.

A questão, então, é definir o que deveríamos descrever, dada a imprecisão de nossa percepção sobre 0 fenômeno. As descrições pretendidas não se fazem "neutramente", já supõem um problema que direciona 0 olhar e faz distinguir os índices principais e secundários relacionados. ${ }^{3}$

A resposta a essa dificuldade é justamente 0 que se apresenta como "teoria". Hipotetizando que o lugar de ocorrência da comunicação são as interações humanas e sociais, precisamos estabelecer uma sistemática mínima que ofereça perspectiva comum sobre uma diversidade de interações - fazendo-lhes perguntas similares.

A própria construção do objeto, conforme apresentada no item acima (ver também BRAGA, 2010, 2011), traz já suas perguntas e corresponde a um modo de problematizar o objeto - direcionando o tipo de descrição a ser feita.

A pergunta principal, inerente à própria lógica do conceito foucaultiano de "dispositivo", é: "que sistema de relações podemos encontrar nos dispositivos a serem estudados?". Outro modo de formular essa questão é:

1) "qual a lógica, a regra do jogo que se constata no processo, em seu acionamento social?"

Como, além disso, estou estudando dispositivos interacionais, heuristicamente assumidos como indicado acima, outras perguntas decorrem diretamente dessa construção:

2) que componentes relevantes diferenciados encontramos em diferentes dispositivos?

3) que diferentes objetivos sociais tentam se sobrepor em um mesmo dispositivo?

4) o que a sociedade está tentando aí? (tratase, aqui, das tentativas do processo - o que é diferente de se perguntar o que os participantes da interação estão tentando).

5) como as tentativas dos participantes acioname redirecionam essa "tentativa do processo"?

6) como se apresentam as relações contextuais de circulação no dispositivo em exame?

7) como se apresenta o jogo entre codificações e inferências? 
a. que regras ou códigos estão sendo elaborados nessas tentativas?

b. o que esses códigos viabilizam ou constrangem, na lógica dos objetivos?

c. como os processos tentativos conjunturais lidam com a insuficiência inerente aos códigos? Que espaços, então, são deixados à inferência?

Acredito que tais perguntas permitirão fazer descrições acuradas e singulares, caso a caso - ao mesmo tempo comparáveis em suas variações, pois organizam uma mesma clivagem do objeto.

Trata-se de observar ações e movimentos previstos pelo dispositivo e/ou estrategicamente acionados pelos participantes. Isso está associado a outro ângulo de nossa construção de hipótese: consideramos os episódios comunicacionais como uma forma de ação razão pela qual denominamos a aproximação investigativa de "análise performativa". Observar a performance dos participantes e do dispositivo permitirá esclarecer lógicas, critérios e objetivos do processo.

\subsection{Valorações}

0s fenômenos de natureza comunicacional que chamam a atenção dos pesquisadores são frequentemente relacionados a questões humanas e sociais tensas e dramáticas e se apresentam, de algum modo, como críticas. Isso exige tomadas de posição e critérios valorativos - a serem ética e filosoficamente examinados ou simplesmente assumidos em âmbito extra-científico, na própria inserção social prática dos participantes. Sua urgência às vezes nos obriga a assumir valores como prioridade, sem aprofundar o conhecimento.

Um esforço necessário para o desenvolvimento reflexivo do conhecimento comunicacional é evitar a tendência de assumir preliminarmente um critério de valor (abstrato ou comparativo) para tentar explicar um episódio comunicacional, uma situação ou uma característica do processo de comunicação. Nessa situação, o esforço explicativo se concentraria em assumir um valor - social, cultural, educacional, artístico; e em demonstrar que os processos observados se apresentam em determinadas relações com 0 valor referenciado, favorecendo-o ou se contrapondo a ele. Tais relações entre valor e realidade são tomadas então como "o conhecimento" que se impõe sobre 0 processo ou episódio em estudo.

Mas esse conhecimento, enviesado pelas posições valorativas apriorísticas, nos parece excessivamente limitado. Ainda que nos ofereça determinadas percepções sobre alguns aspectos do objeto de conhecimento, isso impede uma percepção rigorosa e específica sobre as lógicas mesmo do que se quer conhecer.

Precisamos então de buscar modos e táticas de aproximação que resultem mais descritivo- 
inferenciais, objetivando perceber as "lógicas internas" da ação comunicacional do processo ou episódio; e as lógicas de inserção em seu contexto significativo, em vez de decidir genericamente sobre os valores e desvalores do processo.

Isso não corresponde a pretender uma ciência neutra, nem a defender que a pesquisa deva ser movida por uma curiosidade contemplativa. Ao contrário, sabemos que os problemas que movem a investigação nas CHS são estimulados desde 0 início pelas posições que os constroem. 0 que se critica é que uma pesquisa se limite ao movimento confirmador de posições préassumidas, dispensando-se de apreender descritivamente 0 que ocorre. A perspectiva, aqui, é que nossas posições axiológicas - quando voltadas para a construção de conhecimento devem, diversamente, exigir um conhecimento rigoroso daquilo que nossos valores fazem examinar, e não restringir o conhecimento aos aspectos que os confortam.

As possibilidades descritivas que buscamos com nossa construção do objeto oferecem base para 0 atendimento dessa segunda condição. Antes de, genericamente, julgar positivo ou negativo um processo, 0 gesto de pesquisa pede que se dê lugar a uma pergunta mais praticamente descritiva: o que acontece aí, em termos interacionais? Que lógicas estão sendo acionadas e experimentadas socialmente? Essa premissa nos parece particularmente relevante nos estudos de midiatização pois, diante de dispositivos recentes e em construção, é fácil recair em julgamentos, propostos como se fossem conhecimentos.

Com base nas inferências pós-descritivas (isto é, decorrentes de inquirição e não de critérios categóricos apriorísticos) é que devemos então reinscrever nossas preocupações éticovalorativas - agora informadas pela ampliação de conhecimento que desenvolvemos sobre a coisa. Isso, evidentemente, amplia a potencialidade crítica que se possa ter a respeito, uma vez que a qualidade crítica é sempre relativa ao rigor da percepção sobre o objeto criticado. Em vez de um valor prévio e genérico, teremos uma valoração subsequente e específica, fundamentada nas descobertas obtidas.

\subsection{Transversalidade}

0 objeto proposto tem, efetivamente, uma pretensão de amplitude, ao assumir que as interações sociais são o lugar de ocorrência da comunicação; e que tais interações são observáveis de modo sistemático pelo estudo dos dispositivos interacionais que aí se elaboram e se modificam.

Dispor desse conceito - elaborado diretamente com o objetivo de um "olhar comunicacional" (por mais tosco que ainda se apresente 0 instrumento de observação) - nos permite fazer perguntas à realidade empírica que não seriam feitas no âmbito de diversas CHS, por mais que, em 
seus âmbitos específicos, se preocupem, como efetivamente se preocupam, com o fenômeno comunicacional enquanto variável interveniente no espaço de suas preocupações próprias.

Essa abrangência não corresponde, entretanto, a substituir nem a subsumir perguntas mais habitualmente feitas para objetos empíricos próximos. Mas sim a poder dialogar com estas, estimulando, pelo desafio posto, outras perguntas e tensionamentos de sentido inverso.

Estamos propondo, assim, uma espécie de objeto mínimo - bastante próximo do senso comum - a respeito do que seja "comunicação". É por isso que podemos encontrar, na diversidade de objetos empíricos estudados por colegas pesquisadores da área, a presença desse elemento interacional ou a referência a algum sistema (diversificadamente constituído e interpretado) que "faz mover" a interação.

A constituição do objeto de investigação "dispositivos interacionais" deve permitir, portanto, dialogar, tensionar e ser tensionado por essas outras construções empírico-reflexivas. Essa possibilidade, buscada na construção da hipótese heurística, é o que denominamos "transversalidade". Mais que abrangente, tenho a expectativa de que 0 objeto de estudo possa se mostrar transversal.

0 objetivo de transversalidade da hipótese heurística aparece em dois aspectos. Primeiro, pretende-se fazer inferências transversais a objetos diferenciados (por outras perspectivas), reunidos na pesquisa como casos de um processo geral comum, que é o acionamento de dispositivos interacionais. Segundo, busca-se atravessar diferentes modos de olhar - que são as proposições sobre objetos próximos, feitas por outros pesquisadores em função de suas teorias específicas acionadas.

A expectativa de produtividade dessa abordagem decorre da possibilidade de descrever, em clivagem transversal, processos que são diversificadamente perguntados e explicados por outras abordagens. Não se pretende que tais descrições transversais sejam superiores às demais - mas sim que permitam comparações (em nível descritivo, e não de crença teórica), viabilizando o desenvolvimento de remissões e de desafios mútuos.

\section{A proposição teórica}

Na perspectiva de Popper, uma hipótese proposta para enfrentar um problema de conhecimento é já uma teoria - isso porque as teorias mantêm sempre essa provisoriedade, tentativa, na solução dos problemas a que respondem.

Podemos então assumir que as perspectivas acima prefiguradas efetivamente se articulam como uma proposição teórica, desde a construção do objeto até os objetivos da investigação. A questão que estamos trabalhando como eixo deste artigo é: que tipo de proposição 
se caracteriza aí e como se inscreve no quadro das diversificadas perspectivas de produção de conhecimento no campo da Comunicação.

A previsão de "desenfatizar" (mas não abandonar) explicações diretamente derivadas de teorias estabelecidas decorre da perspectiva de que estas, tipicamente, assumem como essenciais determinados ângulos privilegiados do processo comunicacional complexo, tendendo a desconhecer ou tomar como secundários outros ângulos. Exatamente porque não dispomos de critérios muito seguros diante de diferentes "essencialidades", parece prudente não jogarmos todas as fichas em qualquer delas. Isso não corresponde a recusar validade e interesse para tais estudos. Ao contrário, no âmbito da "ciência normal" (cf. Thomas Kuhn, 2011) em que tais explicações se desenvolvem, toda uma variedade de aspectos do "comunicacional" têm tido seu conhecimento muito desenvolvido.

Por outro lado, tais conhecimentos tendem a reforçar o âmbito teórico específico em que são elaborados. Se considerarmos que tais perspectivas (em quaisquer de seus âmbitos) não chegam a consolidar um conhecimento propriamente comunicacional, devemos reconhecer que nos restringirmos à ciência normal não parece suficiente para 0 desenvolvimento pleno do campo.

Isso não significa que devemos nos situar diretamente no âmbito contraposto ao da ciência normal, que é a "ciência revolucionária" ou "de ruptura". ${ }^{4}$ A ruptura pressupõe um período histórico de ciência normal em curso, no decorrer do qual acabam se esgotando as possibilidades produtivas de teorias bem sustentadas, que trabalhavam toda uma variedade de enigmas de conhecimento construídos na lógica mesmo dessas teorias.

Ora, sabemos que o âmbito da Comunicação não dispõe de teorias estabelecidas suficientemente abrangentes e consolidadas para ter gerado uma coleção organizada de enigmas. Sabemos também que as teorias mais acionadas pela área não esgotaram a geração de enigmas que podem ser abordados segundo suas lógicas.

Estaríamos assim, aparentemente, em um espaço paradoxal, em que nenhuma das duas alternativas seria preferida. ${ }^{5} \mathrm{Na}$ verdade as coisas talvez sejam mais simples. 0 campo da Comunicação - justamente como espaço de potencialidades "em aberto" de conhecimento

Popper (2009, p. 27) considera que toda ciência é revolucionária: "substituição de antigas teorias por teorias mais recentes". Kuhn (2011, p. 288), igualmente valorizando os momentos de ruptura de paradigmas, assinala entretanto a produtividade dos períodos de ciência normal: solução de enigmas que pressupõem "a teoria corrente como a regra do jogo".

Não excluímos a ocorrência inesperada de teorias revolucionárias - isto é, que venham a gerar toda uma problemática nova no âmbito do campo. Mas tais coisas só se constatam a posteriori. 
- se encontraria em um terceiro espaço, muito propício para "teorias em tentativa". ${ }^{6}$

Essa possibilidade é contemplada por Popper, na circunstância em que não se compreende com clareza o próprio problema a ser enfrentado situação que nos parece muito próxima da que caracteriza o campo de estudos em Comunicação:

[...] há apenas uma maneira de aprender e compreender um problema que ainda não compreendemos - e essa maneira é tentar resolvê-lo e falhar. Isso pode parecer paradoxal. Pois como podemos tentar resolver um problema que nem sequer compreendemos? (POPPER, 2009, p. 253).

Apesar da aparência paradoxal, a proposição faz sentido porque o resultado principal da sequência "problema > tentativa de solução (teoria) > crítica (falibilidade)", para Popper, é justamente um novo problema, mais elaborado - ainda que as teorias, tentativas, falhem. A pesquisa em curso assume esse caráter de teoria como tentativa de enfrentamento de um problema complexo.

Popper (2009, p. 252, grifo do autor) propõe ainda que "compreender uma teoria significa [...] compreendê-la como uma tentativa de resolver um determinado problema". Por extensão, deve ser possível esclarecer uma proposição teórica em elaboração a partir do tipo de problema que esta procura enfrentar.

\section{0 problema a enfrentar}

0 problema da investigação em curso corresponde a apreender os sistemas de interação dos casos a serem estudados descrevendo suas características e fazendo inferências transversais que possam encompassar suas variações. A teoria acionada para essa pesquisa propõe uma construção do objeto e modos de inquirição com essa finalidade.

Entretanto, o propósito dessa construção é nos aproximar de outro problema, mais abrangente - que é o interesse de estimular a busca de perguntas mais especificamente comunicacionais. Nesse aspecto, o objetivo é o de testá-las e produzir perguntas melhores, que possam ser percebidas: a) como questões propriamente comunicacionais; b) e como questões que tenham alguma transversalidade - para certa diversidade de objetos comunicacionais. É essa possibilidade que inscreve a proposição no quadro das perspectivas de produção de conhecimento do campo.

Como assinalamos no início deste item, todas as teorias são, genericamente, tentativas (expostas à falibilidade). Aqui, usamos o qualificativo em perspectiva estrita, por duas razões específicas: a) trata-se de uma heurística - formulação voltada para a descoberta e não para explicações; e b) a "tentativa" é a de ampliar a percepção e a construção do próprio problema. 
Essa é uma pretensão forte, na medida em que assumimos (de modo não positivista) que uma disciplina de conhecimento se funda não na especificidade de um método de investigação sobre um objeto "separado"; mas sim na especificidade das perguntas que faz a objetos do mundo, em geral, para os quais tais perguntas possam ser pertinentes - funcionando como instrumento e motivação de descoberta.

Assim, embora estejamos, aí, trabalhando nas bases elementares da Comunicação, a questão não é a de esclarecer o que seja o "comunicacional" nem a de tentar definir o que seria "0 objeto" desse âmbito de conhecimento. Mas sim, a de buscar perspectivas para uma determinada ampliação da produtividade dos conhecimentos, desafiando a área a produzir novas perguntas.

Não apostando na ocorrência de um "gesto epistemológico" que abra repentinamente frentes de problematização radicalmente superadoras; e acreditando que um conhecimento bastante interessante vem sendo diversificadamente produzido pela área de estudos, percebemos como principal problema prático da área a indiferença mútua de tais conhecimentos.

0 tensionamento mútuo de tais perspectivas deve ser produtivo para 0 desentranhamento de questões comunicacionais, a serem "destiladas" a partir do cotejo entre visadas diferenciadas que sem isso arriscam ficar acantonadas em seus modos de olhar e perguntar "especializados". É relevante para a área que tais perspectivas possam se perceber como "interpretações concorrentes" (CAMPBELL, 2005, p. 7). Para isso, é importante gerar âmbitos de comparabilidade.

É claro que tal geração é tentativa, pois não se trata de explicitar abstratamente um lugar específico em que as diversas teorias e abordagens se encontram - esse seria 0 objetivo do gesto epistemológico de abrangência. Trata-se antes de gerar descrições e perguntas sobre observáveis que - na medida em que possam efetivamente dialogar com angulações diversas - trabalharão no sentido de desafiar a dispersão. A ideia é que qualquer das subáreas e das linhas em que conhecimentos parciais são desenvolvidos, se desafiada por perspectivas de outras angulações que estejam também (por seu ângulo específico) preocupadas com a questão comunicacional, tenderá a gerar perguntas mais agudamente "comunicacionais".

Baseada nessa premissa, a pesquisa desenvolve sua problematização e suas hipóteses (sua proposição teórica) com o objetivo de gerar perguntas que possam, por sua vez, tensionar proposições em uma diversidade de subáreas do campo.

0 que se pode justificar como "base objetiva" (como proposto na introdução do artigo) não é, evidentemente, uma pretensão de que isso venha a funcionar - mas sim a coerência entre a elaboração teórica e o problema abrangente assinalado. É o problema, em si, que afirmamos 
ser objetivamente relevante. A heurística proposta é apenas uma tentativa de enfrentamento.

Com um agradecimento especial a Luiz

Signates, pela exigência de reflexão que sua observação determinou.

\section{Referências}

BRAGA, José Luiz. Dispositivos interacionais. In: ENCONTRO ANUAL DA COMPÓS, 20., 2011, Porto Alegre. Anais eletrônicos... Porto Alegre: Compós, 2011. Disponível em: www.compos.org.br (Biblioteca, Epistemologia da Comunicação, 2011). Nem rara, nem ausente - tentativa. Matrizes, São Paulo, v. 4, n. 1, p. 65-81, 2010. Comunicação, disciplina indiciária. Matrizes, São Paulo, v. 1, n. 2, p. 73-88, 2008.

CAMPBELL, Donald T. Apresentação. In: YIN, Robert.

Estudo de Caso: planejamento e métodos. Porto Alegre: Bookman/Artmed, 2005.

DELEUZE, Gilles. Qu'est-ce qu'un dispositif? In:

MICHEL Foucault philosophe. Rencontre Internationale. Paris 9, 10, 11 janvier 1988. Paris: Éditions du Seuil, 1989.

FOUCAULT, Michel. The confession of the flesh.

Entrevista. In: . Power/Knowledge selected interviews and other writings. U.S.A., Ed. Colin Gordon, p. 194-228, 1980.

KESSLER, Frank. Notes on dispositif. 2006.

Disponível em: < <ttp://www.let.uu.nl/ Frank.Kessler/ personal/notes\%20on\%20dispositif.PDF > . Acesso em: 04 ago. 2010.

KUHN, Thomas. A tensão essencial. São Paulo, Editora Unesp, 2011
POPPER, Karl. O Mito do Contexto: em defesa da ciência e da racionalidade. Lisboa, Edições 70, 2009. RAFFNSOE, Sverre. Qu'est-ce qu'un dispositif? L'analytique sociale de Michel Foucault, Canadian Journal of Continental Philosophy, v. 12, n. 1, p. 44-66, 2008. 
A tentative theory

\section{Abstract}

Theoretical propositions related to an empirical research are the focus of this article. The paper discusses, preliminarily, the heuristic hypothesis that directs the research: the concept of interactional devices, characterized as the common empirical factor to arrange an apparently chaotic diversity of communication processes. This heuristic deals with the relationship between episodes and communication devices; encoded and inferential elements present in the device; and basic conditions for methodological approach, concerning descriptions, values and transversality. To explain the tentative theory proposed, the paper relates the hypothesis to the specific problem of ongoing research, and to an all-encompassing issue of knowledge in the area of Communication studies. This general issue covers the research and provides the meaning of the theoretical proposition.

\section{Keywords}

Interactional devices. Epistemology.

Communications Research.

\section{Una teoría tentativa}

\section{Resumen}

Proposiciones teóricas involucradas en una investigación empírica constituyen el foco de este artículo. El documento discute preliminarmente la hipótesis heurística que direcciona la investigación: el concepto de dispositivos de interacción, caracterizado como un factor empírico común para organizar una diversidad aparentemente caótica de procesos de comunicación. A partir de esa heurística, son tratadas las relaciones entre episodios comunicacionales y dispositivos; elementos codificados y inferenciales en el dispositivo; y condiciones básicas para aproximación metodológica, referentes a descripciones, valoraciones y transversalidad. Con base en estos elementos, el artículo relaciona la teoría tentativa al problema específico de la investigación en curso; y a una cuestión amplia de conocimiento en el campo de estudios en Comunicación. Ese problema general orienta el proyecto y proporciona el significado de la proposición teórica.

\section{Palabras claves}

Dispositivos de Interacción. Epistemología. Investigación en Comunicación 


\section{Expediente}

A revista E-Compós é a publicação científica em formato eletrônico da Associação Nacional dos Programas de Pós-Graduação em Comunicação (Compós). Lançada em 2004, tem como principal finalidade difundir a produção acadêmica de pesquisadores da área de Comunicação, inseridos em instituições do Brasil e do exterior.
E-COMPÓS I www.e-compos.org.br I E-ISSN 1808-2599

Revista da Associação Nacional dos Programas de Pós-Graduação em Comunicação.

E-compós, Brasília, v.15, n.3, set./dez. 2012.

A identificação das edições, a partir de 2008 , passa a ser volume anual com três números.

\section{CONSELHO EDITORIAL}

Afonso Albuquerque, Universidade Federal Fluminense, Brasil Alberto Carlos Augusto Klein, Universidade Estadual de Londrina, Brasil Álvaro Larangeira, Universidade Tuiuti do Paraná, Brasil André Luiz Martins Lemos, Universidade Federal da Bahia, Brasil Ângela Freire Prysthon, Universidade Federal de Pernambuco, Brasil Angela Cristina Salgueiro Marques, Faculdade Cásper Líbero (São Paulo), Brasil Antonio Roberto Chiachiri Filho, Faculdade Cásper Líbero, Brasil Arthur Autran Franco de Sá Neto, Universidade Federal de São Carlos, Brasi Benjamim Picado, Universidade Federal Fluminense, Brasi César Geraldo Guimarães, Universidade Federal de Minas Gerais, Brasil Cristiane Freitas Gutfreind, Pontifícia Universidade Católica do Rio Grande do Sul, Brasil

Denilson Lopes, Universidade Federal do Rio de Janeiro, Brasil Eduardo Peñuela Cañizal, Universidade Paulista, Brasil Eduardo Vicente, Universidade de São Paulo, Brasil Eneus Trindade, Universidade de São Paulo, Brasil Erick Felinto de Oliveira, Universidade do Estado do Rio de Janeiro, Brasil Florence Dravet, Universidade Católica de Brasília, Brasil Gelson Santana, Universidade Anhembi/Morumbi, Brasil Gislene da Silva, Universidade Federal de Santa Catarina, Brasil Guillermo Orozco Gómez, Universidad de Guadalajara Gustavo Daudt Fischer, Universidade do Vale do Rio dos Sinos, Brasil Hector Ospina, Universidad de Manizales, Colômbia Herom Vargas, Universidade Municipal de São Caetano do Sul, Brasil Inês Vitorino, Universidade Federal do Ceará, Brasil Jay David Bolter, Georgia Institute of Technology Jeder Silveira Janotti Junior, Universidade Federal de Pernambuco, Brasil John DH Downing, University of Texas at Austin, Estados Unidos José Afonso da Silva Junior, Universidade Federal de Pernambuco, Brasil José Carlos Rodrigues, Pontifícia Universidade Católica do Rio de Janeiro, Brasil José Luiz Aidar Prado, Pontifícia Universidade Católica de São Paulo, Brasil Kelly Cristina de Souza Prudêncio, Universidade Federal do Paraná, Brasil.
Laan Mendes Barros, Universidade Metodista de São Paulo, Brasil Lance Strate, Fordham University, USA, Estados Unidos Lorraine Leu, University of Bristol, Grã-Bretanha Lucia Leão, Pontifícia Universidade Católica de São Paulo, Brasil Malena Segura Contrera, Universidade Paulista, Brasil

Márcio de Vasconcellos Serelle, Pontifícia Universidade Católica de Minas Gerais, Brasil

Maria Aparecida Baccega, Universidade de São Paulo e Escola Superior de Propaganda e Marketing, Brasil

Maria Ataide Malcher, Universidade Federal do Pará, Brasil

Maria das Graças Pinto Coelho, Universidade Federal do Rio Grande do Norte, Brasil Maria Immacolata Vassallo de Lopes, Universidade de São Paulo, Brasil Maria Luiza Martins de Mendonça, Universidade Federal de Goiás, Brasi Mauro de Souza Ventura, Universidade Estadual Paulista, Brasil Mauro Pereira Porto, Tulane University, Estados Unidos Mirna Feitoza Pereira, Universidade Federal do Amazonas, Brasil Nilda Aparecida Jacks, Universidade Federal do Rio Grande do Sul, Brasil Osvando J. de Morais, Universidade de Sorocaba, Brasil Potiguara Mendes Silveira Jr, Universidade Federal de Juiz de Fora, Brasil Renato Cordeiro Gomes, Pontifícia Universidade Católica do Rio de Janeiro, Brasil Robert K Logan, University of Toronto, Canadá

Ronaldo George Helal, Universidade do Estado do Rio de Janeiro, Brasil Rose Melo Rocha, Escola Superior de Propaganda e Marketing, Brasil Rossana Reguillo, Instituto de Estudos Superiores do Ocidente, Mexico Rousiley Celi Moreira Maia, Universidade Federal de Minas Gerais, Brasil Sebastião Guilherme Albano da Costa, Universidade Federal do Rio Grande do Norte, Brasil

Simone Maria Andrade Pereira de Sá, Universidade Federal Fluminense, Brasil Tiago Quiroga Fausto Neto, Universidade de Brasília, Brasil Suzete Venturelli, Universidade de Brasília, Brasil Valerio Fuenzalida Fernández, Puc-Chile, Chile Veneza Mayora Ronsini, Universidade Federal de Santa Maria, Brasi Vera Regina Veiga França, Universidade Federal de Minas Gerais, Brasil

\section{COMISSÃO EDITORIAL}

Adriana Braga I Pontifícia Universidade Católica do Rio de Janeiro, Brasil Felipe Costa Trotta I Universidade Federal Fluminense, Brasil

\section{CONSULTORES AD HOC}

Ana Carolina Escosteguy, Pontifícia Universidade Católica do Rio Grande do Sul, Brasil Bruno Campanella, Universidade Federal Fluminense, Brasil

Edison Gastaldo, Universidade Federal Rural do Rio de Janeiro, Brasil Elizabeth Duarte, Universidade Federal de Santa Maria, Brasil Roseli Figaro, Universidade de São Paulo, Brasil

EDIÇÃO DE TEXTO E RESUMOS I Susane Barros

SECRETÁRIA EXECUTIVA I Juliana Depiné

EDITORAÇÃo ELETRÔNICA I Roka Estúdio

TRADUÇ̃̃o I Sieni Campos e Markus Hediger
COMPÓS I www.compos.org.br

Associação Nacional dos Programas de Pós-Graduação em Comunicação

Presidente

Julio Pinto

Pontifícia Universidade Católica de Minas Gerais, Brasil juliopinto@pucminas.br

Vice-presidente

Itania Maria Mota Gomes

Universidade Federal da Bahia, Brasil

itania@ufba.br

Secretária-Geral

Inês Vitorino

Universidade Federal do Ceará, Brasil

inesvic@gmail.com 